\title{
O desenvolvimento da ecologia no Brasil
}

\author{
Rogério Parentoni MARTINS ${ }^{*, * *}$, Carlos Araújo LIMA ${ }^{* * * * *}$
}

\begin{abstract}
RESUMO
Para o desenvolvimento da ecologia no país é necessário considerar quatro problemas fundamentais: 1. A restrita contribuição dos ecólogos brasileiros para desenvolvimento teórico da ecologia; 2 . As dificuldades que os integrantes dos programas de pós-graduação têm em reconhecer a identidade intelectual da ecologia e desenhar os contornos que definem sua abrangência; 3 . Envolvimento de profissionais sem formação ecológica específica, por exemplo, engenheiros sanitários, agrônomos e florestais, arquitetos, sociólogos e pedagogos em práticas ambientais, muitas vezes exercendo atividades no âmbito da competência de ecólogos, mas ignorando conhecimentos ecológicos fundamentais para as soluções que propõem; 4. Por isso mesmo, os ecólogos devem entender não só a necessidade de uma abordagem interdisciplinar dos problemas ambientais, mas também identificar e diferenciar o papel efetivo da teoria ecológica na construção e aplicação do conhecimento interdisciplinar.
\end{abstract}

Palavras - chave: Desenvolvimento da ecologia, Interdisciplinaridade, Teoria ecológica

\begin{abstract}
Four shortcomings prevent the improvement of ecology in Brazil: 1. Brazilian ecologists are not contributing significativelly to theoretical ecology; 2. Members and students of gratuate programs in ecology have difficulties to recognize the identity of ecology; 3 . Non-ecologists working on environmental problems lack fundamental knowledge in ecology; 4. Ecologists do not recognize interdisciplinarity as essencial to solve environmental problems.
\end{abstract}

Key-words: Ecology improvement, Interdisciplinarity, Ecology Theory

* Representantes da Área de Ecologia e Meio Ambiente da CAPES.

** Laboratório de Ecologia e Comportamento de Insetos, Departamento de Biologia geral, ICB-UFMG, Cx. Postal, 486, 30.161-970, Belo Horizonte, MG, e-mail:wasp@mono.icb.ufmg.br.

*** Instituto Nacional de Pesquisas da Amazônia (INPA), Cx. Postal 478, 69 011-970, Manaus, AM. 


\section{Introdução}

Há quatro problemas fundamentais a serem enfrentados pelos pesquisadores e professores de ecologia: 1 . A restrita contribuição dos ecólogos brasileiros para desenvolvimento teórico da ecologia; 2. Em parte como um resultado do primeiro problema, as dificuldades que os integrantes dos programas de pós-graduação têm em reconhecer a identidade intelectual da ecologia (Coutinho, 1996) e de conseqüentemente desenhar os contornos que definem sua abrangência; 3 . Envolvimento de profissionais sem formação ecológica, por exemplo, engenheiros sanitários, agrônomos e florestais, arquitetos, sociólogos e pedagogos em projetos ambientais, muitas vezes exercendo atividades no âmbito de nossa competência ou ignorando aspectos ecológicos fundamentais nas soluções que propõem. Isso ocorre por que os ecólogos têm dificuldades em reconhecer e definir a identidade intelectual da disciplina e porque aqueles profissionais estão rapidamente incorporando, à revelia, a "ecologia ou meio ambiente" como escopo de suas atividades profissionais; 4. Por isso mesmo, os ecólogos devem entender não só a necessidade de uma abordagem interdisciplinar dos problemas ambientais, mas também identificar e diferenciar o papel efetivo da teoria ecológica na sua construção e aplicação.

Discussões de tais problemas fundamentais deveriam ocorrer periodicamente como uma atividade dos cursos de pós-graduação. Mas, ao contrário, são geralmente relegadas a segundo plano, em virtude das prioridades estabelecidas, em parte, pela estrutura das universidades e institutos de pesquisa e também pela falta de interesse de participação por parte dos pesquisadores que são excessivamente especializados.

Para que as futuras gerações de ecólogos possam associar o valor dessas discussões com o desenvolvimento, maturidade e credibilidade da ecologia no Brasil, cabe-nos a tarefa de incluí-las na pauta de discussões prioritárias dos programas de pós-graduação. Deste modo, os jovens aspirantes a ecólogos se sentirão estimulados, cada vez mais, a identificar e ultrapassar as limitações que dificultam o desenvolvimento da ecologia brasileira e sua credibilidade como um instrumento de desenvolvimento econômico e social do país.

\section{Os quatro problemas}

O ano 2000 marcará os 24 anos de desenvolvimento da ecologia no Brasil. Antes de 1976, quando se iniciaram os cinco primeiros cursos de pós-graduação [INPA (Ecologia e Biologia de água doce e pesca interior) UNB, UFSCAR, UNICAMP], a denominada pesquisa ecológica no Brasil era desenvolvida por zoólogos e botânicos sem formação teórica específica em ecologia, a exemplo das pesquisas ecológicas sobre a vegetação de cerrado realizadas por fisiólogos vegetais.

Muito embora nesses 24 anos essa situação tenha se aperfeiçoado signficativamentemente, devido ao trabalho desenvolvido nos cursos de pós-graduação brasilieros e à formação de doutores em instituições estrangeiras, ainda é desproporcional a magnitude da aquisição de conhecimentos empíricos comparada ao conhecimento teórico desenvolvido por ecólogos brasileiros. Nesse sentido, podemos dizer que boa parte das nossas pesquisas ecológicas é descritiva. Deixamos claro, que não discriminamos o conhecimento descritivo, considerando-o de segunda categoria, posto que sendo informação científica de boa qualidade, especialmente sobre história natural, sua utilidade é incontestável. Porém, quanto os ecólogos brasileiros têm avançado na elaboração de novas teorias? Quais foram as teorias relevantes produzidas nesses últimos anos pelos ecólogos brasileiros? Consultando freqüentemente, nos últimos 20 anos, periódicos ecológicos de primeira linha, verificamos que a contribuição teórica dos ecólogos brasileiros é muito restrita. Por esse motivo, cremos ser a identificação dos obstáculos que dificultam nosso progresso teórico, um primeiro passo relevante para promover o desenvolvimento da ecologia no Brasil.

O reconhecimento da identidade intelectual da ecologia implica no conhecimento das principais teorias e hipóteses que caracterizam o, às vezes chamado, corpo teórico da disciplina. Esse é o fundamento de estudos que pretendem testar hipóteses ecológicas propostas e avançar na elaboração de novas hipóteses elucidativas de aspectos ecológicos regionais ou de teorias mais abrangentes. Nossa experiência como analista de projetos em ecologia, para várias instituições brasileiras de fomento à pesquisa, indica, na maioria dos casos, a ausência de conexões teóricas nas propostas de pesquisa; 
a falta de testes de hipóteses e conseqüentemente do desenho experimental pertinente. Essa constatação, portanto, reforça nossa crença de que estamos produzindo um número desproporcionalmente maior de conhecimento descritivo do que teórico. Por esse motivo, a formação de pesquisadores teoricamente orientados, que sejam aptos a desenvolver projetos de longo prazo, deve ser uma prioridade para que o aprimoramento dos cursos de pós-graduação em ecologia seja obtido. Essa alternativa é obviamente preferível à mais rápida, que é a da produção de numerosos trabalhos quick and dirty. É falsa a impressão de maturidade científica às vezes transmitida por currículos com um grande número de trabalhos pouco consistentes, publicados em revistas pouco exigentes. Adicionalmente, há ainda pesquisadores que não expõem os resultados de seu trabalho à crítica internacional, concentrando-os em periódicos regionais, sob o pretexto, algumas vezes válido, de que o interesse da pesquisa é regional. Enfim, caso os cursos consigam perceber claramente a identidade intelectual da ciência que produzem, certamente formarão melhores alunos e produzirão um conhecimento ecológico de melhor qualidade. Assim, a ecologia no Brasil poderá dar um salto de qualidade nos próximos 10 anos.

Frequientemente ouvimos de colegas advertências sobre a "invasão do nosso mercado de trabalho" por outros profissionais, principalmente alguns engenheiros que incorporaram em sua prática profissional a dimensão ecológica ou mais vagamente "ambiental", como alguns preferem. Caso isso esteja ocorrendo, com frequiência, talvez um dos motivos é o de que não temos competência para resolver problemas práticos, seja por carência de fundamentação teórica consistente, seja pela inexperiência em lidar com situações práticas em nossa formação acadêmica. Para ocuparmos esse "nicho" temos que voltar nossa atenção para as situações ambientais regionais, as quais devem ser estudadas em busca de soluções. Isso quer dizer que, na configuração dos projetos de pesquisa, esses tipos de situações devem ser privilegiados. Mais uma vez é importante reconhecer nossas deficiências nesse aspecto importante e a necessidade da concentração de esforços persistentes para suprí-las. Tais esforços requerem a reestruturação do modo de ensinar e de pesquisar, substituindo o totalmente acadêmico pelo necessário acadêmico em um con- texto prático. Observe-se que o sucesso de uma "ecologia aplicada" depende de uma fundamentação teórica explícita, o que reforça ainda mais o que foi dito anteriormente. Vale dizer, no entanto, que esse não é um problema particular da ecologia brasileira, mas também da ecologia mundial.

Enfim, há um reconhecimento crescente de que os problemas ecológicos são complexos, não apenas devido à natureza intrínseca dos sistemas biológicos, mas porque o comportamento desses sistemas são ainda influenciados por outros níveis de complexidade culturais (senso antropológico), sociais, econômicas e políticas. O ecólogo acadêmicamente competente, mas sem uma visão do alcance social do seu trabalho, tarde lamentará os ônus decorrentes de sua visão estreita. Para que o ecólogo trabalhe dentro em um contexto no qual possa avaliar a influência de contingências sociais, econômicas, políticas e culturais em seu trabalho e vice-versa, é indispensável que se comunique com profissionais de outras disciplinas. Nenhum problema ecológico complexo será satisfatoriamente resolvido apenas com a interveniência da ecologia. Portanto, dado essa realidade contemporânea, resta-nos reconhecê-la e a ela nos adaptarmos, mudando nosso modo estanque de produzir conhecimento. A alternativa é a de reconhecermos os pontos de confluência interdisciplinar, onde identifiquemos nossa participação em conjunto com pesquisadores de outras disciplinas. Não obstante as dificuldades do desenvolvimento de interações interdisciplinares, nesse universo de cientistas especializados, caso nos propusermos a executá-lo nosso trabalho passará a ter um novo significado acadêmico, além de uma maior utilidade social.

Esses quatro problemas da ecologia brasileira contemporânea têm um ponto básico comum - o conhecimento teórico. É perda de tempo insistir na proposição de soluções para problemas ambientais amparados apenas nos conhecimentos empíricos, que a despeito de sua importância óbvia, só têm sentido à luz da teoria, cuja elaboração é uma das principais tarefa do ecólogo.

Agradecimentos: Agradecemos Francisco A. R. Barbosa, Sérvio Pontes Ribeiro, Elder Morato, Maria Eugênia Carvalho Amaral, Frederico Santos Lopes e Cláudia Maria Jacobi pelos comentários construtivos sobre esse texto. 
MARTINS, R. P. O desenvolvimento da ecologia no Brasil

\section{REFERENNCIAS}

COUTINHO, M. Ecology and environmental science in brazilian higher education - graduate programs, research and intelectual identity. São Paulo: NUPES-USP, 1996. 46 p. Documento de trabalho.
PICKETT, S.T.A. J. KOLASSA; C.G. JONES. Ecological Understanding: the nature of theory and the theory of nature. New York: Academic Press, 206 p., 1994. 